\title{
Synaptic interactions between perifornical lateral hypothalamic area, locus coeruleus nucleus and the oral pontine reticular nucleus are implicated in the stage succession during sleep-wakefulness cycle
}

\author{
Silvia Tortorella, Margarita L. Rodrigo-Angulo, Angel Núñez * and Miguel Garzón \\ Departamento de Anatomía, Histología y Neurociencia, Facultad de Medicina, Research Institute, Universidad Autonoma de Madrid, La Paz University \\ Hospital (IDIPAZ), Madrid, Spain
}

Edited by:

Michel A. Steiner, Actelion

Pharmaceuticals Ltd., Switzerland

\section{Reviewed by:}

Rodrigo Espana, Drexel University

College of Medicine, USA

Hiroshi Katsuki, Kumamoto

University Graduate School of

Pharmaceutical Sciences, Japan

\section{${ }^{*}$ Correspondence:}

Angel Nuñez, Departamento de

Anatomía, Histología y

Neurociencia, Facultad de Medicina,

Research Institute, Universidad

Autonoma de Madrid, La Paz

University Hospital (IDIPAZ),

c/ Arzobispo Morcillo 4, 28029

Madrid, Spain

e-mail: angel.nunez@uam.es
The perifornical area in the posterior lateral hypothalamus (PeFLH) has been implicated in several physiological functions including the sleep-wakefulness regulation. The PeFLH area contains several cell types including those expressing orexins (Orx; also known as hypocretins), mainly located in the PeF nucleus. The aim of the present study was to elucidate the synaptic interactions between Orx neurons located in the PeFLH area and different brainstem neurons involved in the generation of wakefulness and sleep stages such as the locus coeruleus (LC) nucleus (contributing to wakefulness) and the oral pontine reticular nucleus $(\mathrm{PnO})$ nucleus (contributing to REM sleep). Anatomical data demonstrated the existence of a neuronal network involving the PeFLH area, $\mathrm{LC}$, and the $\mathrm{PnO}$ nuclei that would control the sleep-wake cycle. Electrophysiological experiments indicated that PeFLH area had an excitatory effect on LC neurons. PeFLH stimulation increased the firing rate of LC neurons and induced an activation of the EEG. The excitatory effect evoked by PeFLH stimulation in LC neurons was blocked by the injection of the Orx-1 receptor antagonist SB-334867 into the LC. Similar electrical stimulation of the PeFLH area evoked an inhibition of $\mathrm{PnO}$ neurons by activation of GABAergic receptors because the effect was blocked by bicuculline application into the $\mathrm{PnO}$. Our data also revealed that the LC and PnO nuclei exerted a feedback control on neuronal activity of PeFLH area. Electrical stimulation of LC facilitated firing activity of $\mathrm{PeFLH}$ neurons by activation of catecholaminergic receptors whereas $\mathrm{PnO}$ stimulation inhibited PeFLH neurons by activation of GABAergic receptors. In conclusion, Orx neurons of the PeFLH area seem to be an important organizer of the wakefulness and sleep stages in order to maintain a normal succession of stages during the sleep-wakefulness cycle.

Keywords: orexin, orexin-1 receptor, GABAergic receptors, catecholaminergic receptors, wakefulness, REM sleep

\section{INTRODUCTION}

Sleep and wakefulness are two mutually exclusive states that cycle with both ultradian and circadian periods. The brain mechanisms underlying the organization of the sleep-wakefulness cycle remain unclear. Many studies have identified several populations of neurons whose activity correlates with distinct behavioral states (Carter et al., 2012, 2013). The perifornical lateral hypothalamic area (PeFLH) has been implicated in several physiological functions including sleep-wakefulness regulation (McGinty and Szymusiak, 2003; Jones, 2008); this area contains a heterogeneous population of neuronal groups as reflected by both their state-dependent discharge properties and their neurotransmitter phenotypes. Among others, these cells express hypocretin/orexin (Orx), melanin-concentrating hormone, $\gamma$-aminobutyric acid (GABA) or glutamate (Vaughan et al., 1989; Bittencourt et al., 1992; de Lecea et al., 1998; Sakurai et al., 1998; Abrahamson and Moore, 2001; Rodrigo-Angulo et al., 2008). Orx neurons, mainly located in the perifornical (PeF) nucleus, have been extensively studied and implicated in the facilitation and/or maintenance of arousal (Alam et al., 2002; Koyama et al., 2003; Siegel, 2004; Sakurai, 2005; Takahashi et al., 2005; Sasaki et al., 2011); they are maximally active during active wakefulness and virtually cease firing during both slow wave sleep and rapid eye movement (REM) sleep (Lee et al., 2005a; Mileykovskiy et al., 2005).

Hypothalamic Orx projections make asymmetrical synaptic contacts with their target neurons in numerous brain areas implicated in the control of sleep-wakefulness cycle (Peyron et al., 1998; Horvath et al., 1999). Excitatory Orx effects have been demonstrated in neurons of arousal-related structures including the locus coeruleus (LC) nucleus (Horvath et al., 1999; Eggermann et al., 2001; Marcus et al., 2001; Burlet et al., 2002; Yamanaka et al., 2002; España et al., 2005; Cid-Pellitero and Garzon, 2011) where Orx promotes wakefulness (Bourgin et al., 2000; España et al., 2001; Thakkar et al., 2001; Xi et al., 2001). This effect may 
be due to an excitatory effect of Orx on LC neurons, as has been demonstrated in vitro (Hagan et al., 1999; Horvath et al., 1999; Ivanov and Aston-Jones, 2000; Soffin et al., 2002), suggesting that the effect of Orx on LC neurons may facilitate the arousal state.

Orx axon terminals and Orx receptors have also been identified in cholinoceptive areas of the pontine reticular formation involved in REM sleep generation (Greco and Shiromani, 2001; Marcus et al., 2001; Willie et al., 2003). Cholinoceptive neurons located in the ventral part of the oral pontine reticular nucleus $(\mathrm{PnO})$ are involved in the generation and maintenance of REM sleep in rats (Horner and Kubin, 1999; Kohlmeier et al., 2002; Nuñez et al., 2002) and cats (Reinoso-Suárez et al., 1994, 1999, 2001; Garzón et al., 1998). Orx receptor subtypes are expressed in PnO neurons (Greco and Shiromani, 2001; Willie et al., 2003) and activation of such receptors enhances acetyl-choline release in the rat pons (Bernard et al., 2003, 2006). However, iontophoretic application of Orx in the $\mathrm{PnO}$ nucleus induced an inhibition of neuronal activity in anesthetized rats (Nuñez et al., 2006a); this effect was blocked by a previous iontophoretic application of bicuculline, indicating that inhibitory action of Orx involves the activation of $\mathrm{GABA}_{\mathrm{A}}$ receptors.

The above mentioned results suggest that Orx neurons may play a crucial role in the organization of the sleep-wakefulness cycle and consequently, damage to Orx neurons could disrupt the normal succession of sleep-wake stages, as occurs in human narcolepsy and in animal models of this sleep disorder (Peyron et al., 2000; Thannickal et al., 2000). Narcolepsy is a neurological disorder characterized by severe daytime somnolence with a constellation of unusual symptoms that are best understood as intrusions of REM sleep phenomena into wakefulness (Guilleminault and Fromherz, 2005). In agreement with the hypothesis that Orx neurons play a role in narcolepsy these patients also have reduced cerebrospinal fluid levels of Orx (Nishino et al., 2000). Animal models exhibiting symptoms of narcolepsy show loss of Orx neurons or a decrease in Orx levels (Chemelli et al., 1999; Gerashchenko et al., 2001; Hara et al., 2001; Beuckmann et al., 2004). Canines with narcolepsy carry a mutation in the Orx-2 receptor (Lin et al., 1999) and mice with a deletion of this receptor (Willie et al., 2003) also show symptoms of narcolepsy.

The aim of the present study was to examine the synaptic interaction between Orx neurons located in the PeFLH area and different neuronal generators in the brainstem. We hypothesized that cross-talk among LC nucleus (contributing to wakefulness), PnO nucleus (contributing to REM sleep) and PeFLH area would orchestrate the sleep-wakefulness cycle. Anatomical and electrophysiological studies were undertaken to demonstrate this coordination of the sleep-wakefulness cycle.

\section{MATERIALS AND METHODS}

Procedures were approved by the Ethics Board of the Universidad Autonoma de Madrid in accordance with the European Communities Council guidelines (2012/63/UE) on the ethical use of animals with every effort being made to minimize the suffering and number of animals employed. Fifty-five urethane-anesthetized (1.6 g/kg i.p.) Wistar rats (from Iffa-Credo, L'Arbresle, France) weighing 250-300 g were used for the physiological experiments. Animals were placed in a stereotaxic device with controlled body temperature $\left(37^{\circ} \mathrm{C}\right)$. EEG activity was recorded through a macroelectrode stereotaxically placed into the frontal cortex [at $2 \mathrm{~mm}$ rostral to the Bregma and $2 \mathrm{~mm}$ from the midline (Paxinos and Watson, 2007)]. The EEG was filtered between 0.3 and $30 \mathrm{~Hz}$, and amplified. Supplemental doses of the anesthetic were given when a decrease in the amplitude of the EEG delta waves was observed.

\section{UNIT RECORDING AND DRUG APPLICATION}

Single-unit recordings were obtained with tungsten microelectrodes $(2 \mathrm{M} \Omega$ ) or glass micropipettes (World Precision Instruments, Sarasota, USA) filled with $2 \%$ neurobiotin in $0.5 \mathrm{M}$ $\mathrm{NaCl}$ (Sigma) to locate the recording site. Three-barrel glass micropipettes were also used for unit recording and simultaneous application of pharmacological agents by microiontophoresis (see below).

Recording electrodes were placed at the LC nucleus (coordinates from Bregma: A, $-9.3 ; \mathrm{L}, 1.5$ and depth, $7.0 \mathrm{~mm}$ ), the $\mathrm{PnO}$ nucleus (coordinates from Bregma: A, $-8.0 ; \mathrm{L}, 1.0$ and depth, $8.0 \mathrm{~mm}$ ) or at the PeFLH area (coordinates from Bregma: A, $-2.1 ; \mathrm{L}, 1.0$ and depth, $8.0 \mathrm{~mm}$ ) by means of micromanipulators. Extracellular recordings were filtered $(0.3-3 \mathrm{kHz})$, amplified (P15; GRASS Technology, Warwick, USA) and fed into a PC computer for off-line analysis by a Cambridge Electronic Design (CED; Cambridge, UK) 1401 interface at a sampling frequency of $10 \mathrm{kHz}$ for the unit recordings, together with the EEG (sampling frequency of $200 \mathrm{~Hz}$ ). Spike 2 software (CED) was used.

When barrel micropipettes were used, one of the glass capillaries was filled with a solution of $\mathrm{NaCl}(0.5 \mathrm{M})$ in order to record unit activity. A second micropipette was filled with bicucullinemethiodide ( $10 \mathrm{mM}$ in $0.9 \% \mathrm{NaCl}$, pH 3.0, Sigma, St Louis, MO, USA). The remaining micropipette was filled with $0.5 \mathrm{M} \mathrm{NaCl}$ to balance the retention and ejection currents. Each barrel of the three-barreled pipette was connected via a silver wire to a channel on a microiontophoresis current generator (World Precision Instruments) that controlled retention and ejection currents for the drug-filled micropipette. Bicuculline was ejected with a positive current using a single 30 -s pulse of $50 \mathrm{nA}$ and negative retaining currents of $10-20 \mathrm{nA}$ were used to delay drug leakage from the micropipette.

Bipolar stimulating electrodes $(120 \mu \mathrm{m}$ diameter blunt stainless steel wire) were placed at the ipsilateral PeFLH area, LC nucleus or in the PnO nucleus (same coordinates as described above). Electrical stimulation was performed using single rectangular pulses $(0.1-0.3 \mathrm{~ms}, 50-100 \mu \mathrm{A})$ at $0.5 \mathrm{~Hz}$ or pulse trains of 500-ms duration at a frequency of $50 \mathrm{~Hz}$, delivered through a GRASS S88 stimulator.

\section{DRUGS}

The hypocretin-1 receptor antagonist SB-334867 (100 $\mu \mathrm{M}$; $100 \mathrm{nl}$ ) was applied through a $20 \mathrm{G}$ cannula connected to a Hamilton syringe (flow rate: $50 \mathrm{nl} / \mathrm{min}$ ). The dose was similar to previous reports (Erami et al., 2012). Reserpine (methyl reserpate 3,4,5-trimethoxybenzoic acid ester, Sigma Chemical Co., St. Louis, USA) was dissolved in $50 \mu \mathrm{l}$ of glacial acetic acid plus $0.9 \%$ $\mathrm{NaCl}$ (saline). The control solution consisted of saline plus $50 \mu \mathrm{l}$ of glacial acetic acid in saline. Reserpine doses ( 1.0 and $5.0 \mathrm{mg} / \mathrm{kg}$ ) 
were administered subcutaneously (s.c.) in a volume of $1.0 \mathrm{ml} / \mathrm{kg}$ of body weight. Unit recordings were performed $48 \mathrm{~h}$ after the reserpine injection.

\section{ELECTROPHYSIOLOGICAL DATA ANALYSIS}

Analysis of the neocortical EEGs as well as the activity of each neuron was performed off-line in a PC computer. Spike 2 software was used to perform statistical calculations including summed peristimulus time histograms (PSTH), which were calculated using 2-ms bin widths and power spectra of the EEG. Statistical analyses were calculated with Student's two-tailed $t$ tests for unpaired or paired data as required. Differences were considered statistically significant at a level of $95 \%(p<0.05)$. All data are indicated as mean $\pm \mathrm{SEM}$.

\section{ANATOMICAL STUDIES}

At the end of the electrophysiological experiments animals were injected i.p. with an overdose of pentobarbital and perfused transcardially with $4 \%$ paraformaldehyde in phosphate buffer $\mathrm{pH}$ 7.4. Brains were frozen, sectioned at $50 \mu \mathrm{m}$ and collected in two series. In order to confirm the location of the recording electrodes, sections from the first series were processed to reveal the neurobiotin stained neurons: after rinsing in Tris saline buffer (TS) $0.1 \mathrm{M}$ at $\mathrm{pH}$ 7.6, sections were incubated in a 1:150 Elite ABC kit (Vector) dilution in TS and $0.25 \%$ triton $\mathrm{X}-100$ for $3 \mathrm{~h}$ to be developed with $0.05 \% 3-3^{\prime}$ DAB and $0.003 \% \mathrm{H}_{2} \mathrm{O}_{2}$. Sections of the second series were processed for Nissl staining in order to corroborate the location of the stimulating electrodes.

For the anatomical connection tracing studies, retrograde Cholera Toxin-Alexia 594 (CT-A) and 1.5\% Fluoro-Gold (FG) and anterograde FluoroRuby (FR) fluorescents tracers were injected in 16 adult rats of both sexes weighing 250-280 g. Under general anesthesia (a mixture of 50\% ketamine, 40\% atropine, and $10 \%$ valium i.p. $1 \mathrm{ml} / 250 \mathrm{~g}$ ) animals were placed in the stereotaxic frame, and a craniotomy was made. Fluorescent injections were performed in $\mathrm{PnO}$ and LC nuclei, both in the same hemispheric side by means of a $1 \mu$ l Hamilton syringe (flow rate: $40 \mathrm{nl} / \mathrm{min}$ ). In order to avoid contamination and tracer overlapping, injections in $\mathrm{PnO}$ nucleus were made from the contralateral side in an angle of $45^{\circ}$ at coordinates from Bregma: A, -8.4; L, 1.5, and depth, 8.5, according to the (Paxinos and Watson, 2007); $300 \mathrm{nl}$ of CT-A (10 animals), $40 \mathrm{nl}$ of FG (3 animals), and $450 \mathrm{nl}$ of FR ( 3 animals) were delivered in a single pulse. Injections in LC nucleus were performed with a vertical approach using a $1 \mu \mathrm{l}$ Hamilton syringe stereotaxicaly aimed at the coordinates from Bregma: A, -9.6; L, 1.3; and depth 6.8; $50 \mathrm{nl}$ of FG (12 animals), $50 \mathrm{nl}$ of FR (2 animals), and $300 \mathrm{nl}$ of CT-A (2 animals) were delivered. Animals were allowed to survive for 7 days before transcardial perfusion with $4 \%$ paraformaldehyde in $0.1 \mathrm{M}$ phosphate buffer at $\mathrm{pH} 7.3$ followed by increasing concentrations of sucrose solutions in the same buffer. Once removed, brains were stored in $30 \%$ sucrose solution during 5 days for cryopreservation and afterwards sectioned at $40 \mu \mathrm{m}$ on a cryostat; sections were collected in three consecutive series devoted to fluorescence and Nissl staining. The third series was processed for Orx immunolabeling using the avidin-biotin-peroxidase method; sections were incubated with 1:1000 goat anti-Orx antiserum (Santa Cruz) in a solution containing 5\% bovine serum albumin and $30 \%$ normal rabbit serum in Tris buffer $0.1 \mathrm{M}$ at $\mathrm{pH} 7.6$ for $48 \mathrm{~h}$. After this, sections were incubated in 1:400 biotinylated rabbit anti-goat antibody solution (Chemicon) for $2 \mathrm{~h}$ and in 1:150 avidin-biotinperoxidase reagent Elite $\mathrm{ABC}$ kit (Vector) for $1.5 \mathrm{~h}$. The Orx immunoperoxidase was visualized by incubation in $0.05 \% 3-3^{\prime}$ $\mathrm{DAB}$ and $0.003 \% \mathrm{H}_{2} \mathrm{O}_{2}$. Sections were studied under fluorescent or bright field illumination using a Zeiss Axioskop microscope.

\section{RESULTS}

\section{ANATOMICAL RESULTS}

To determine the projections from the PeF area, two retrograde tracers CT-A and FG were injected into the LC and PnO nuclei, respectively (Figures 1A,B). Also, the anterograde FR fluorescent tracer was used. Numerous retrograde labeled neurons were observed in several hypothalamic structures after PnO tracer injections, as we have already reported (España et al., 2005; Nuñez et al., 2006a; Figure 1C). The injections of the anterograde tracer in $\mathrm{PnO}$ nucleus labeled fibers and terminals only in the lateral sector of PeFLH area (Figure 1E). Neurons labeled after retrograde tracer injections in LC nucleus were located in the ventral sector of PeFLH area and intermingled with the fibers and terminals that could be observed after anterograde tracer injections in LC nucleus (Figures 1D,F). In all cases, the presence of double-labeled neurons was very low ( $<0.5 \%$ of labeled neurons).

A schematic drawing of the hypothalamic area depicting differential distribution of retrograde labeled neurons and anterograde labeled fibers after $\mathrm{PnO}$ and LC tracer injections is shown in Figure 2A. As has been previously reported (Nuñez et al., 2006a) Orx immunoreactive neurons were clustered to the PeF nucleus (Figure 2B). In the PeF nucleus we found double-labeled neurons projecting to $\mathrm{PnO}$ (data not shown) or to LC nucleus (Figure 2C) that were also stained for Orx.

\section{PeF ACTIVATION OF LC}

The LC neurons displayed a non-rhythmic discharge pattern with a mean spontaneous frequency of $3.4 \pm 1.0$ spikes/s $(n=40)$. The recording site was established by iontophoretic injection of neurobiotin through the recording micropipette (Figure 3, inset).

Trains of electrical stimulus delivered in the PeFLH area $(50 \mathrm{~Hz} ; 50 \mu \mathrm{A} ; 500 \mathrm{~ms}$ of duration) increased the mean firing rate of LC neurons from $3.4 \pm 1.0$ to $9.8 \pm 1.7$ spikes/s, measured $10 \mathrm{~s}$ after the stimulation train $(p<0.001$; Figures 3A,C). The excitatory effect was observed in $64 \%$ of LC neurons (32 out of 50 cells), and could last up to $30 \mathrm{~s}$. The EEG pattern changed from continuous slow waves evoked by the anesthetic to a faster activity evoked by PeFLH stimulation (Figure 3A). In spontaneous conditions the percentage of delta waves $(1-4 \mathrm{~Hz})$ in the EEG was $98.6 \pm 1.8 \%$ and the percentage of faster $(>4 \mathrm{~Hz})$ waves was $1.4 \pm$ $0.9 \%$. During the period of $10 \mathrm{~s}$ after the PeFLH stimulation train the proportion of delta waves decreased to $67.3 \pm 3.4 \%$ and the percentage of $>4 \mathrm{~Hz}$ waves increased to $32.7 \pm 4.6 \%(p<0.001)$, indicating that the PeFLH stimulation induced an activation of the EEG.

The excitatory effect evoked by PeFLH stimulation in LC neurons was blocked by the injection of the Orx-1 receptor antagonist SB-334867 into the LC nucleus. The SB-334867 was applied by 

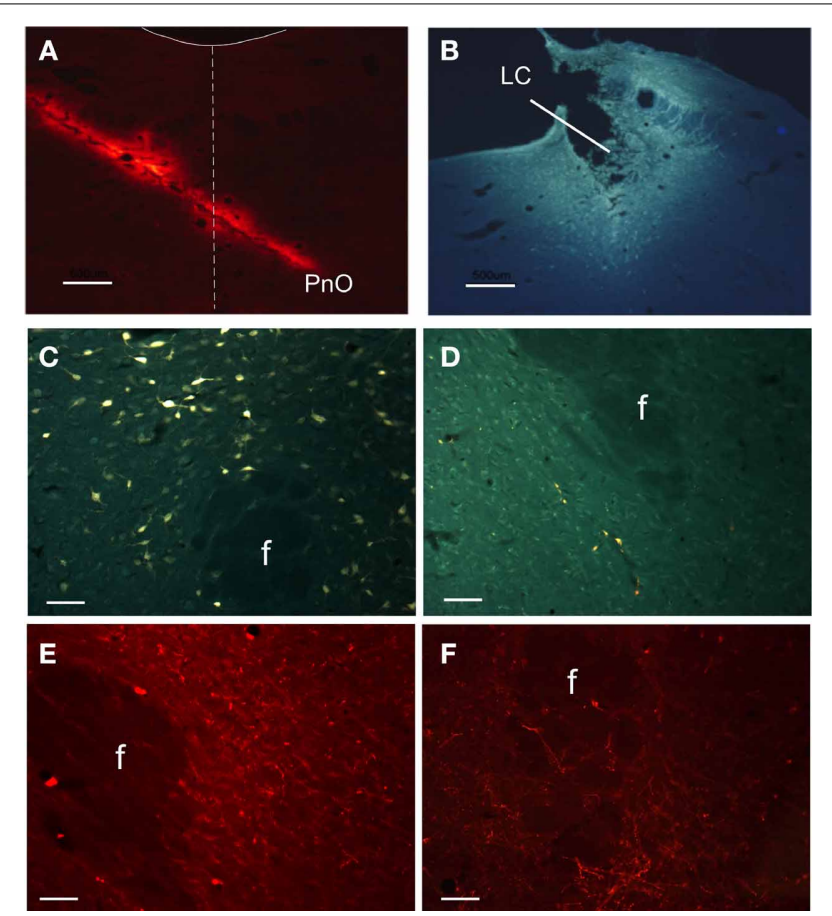

FIGURE 1 | Anatomical projections between PeFLH area and LC or PnO nuclei. (A) Microphotograph showing a representative case of FR injection aimed at $\mathrm{PnO}$ from the contralateral side. Dash line indicates midline; solid line indicates the IV ventricle contour. (B) Microphotograph of a FG injection aimed at LC. (C,D) Microphotographs showing labeled neurons in the PeF area after FG injection in $\mathrm{PnO}$ nucleus (C) and LC nucleus (D). (E,F) Microphotographs of two cases showing fiber terminals after FR injections in $\mathrm{PnO}$ nucleus (E) and LC nucleus (F). f: fornix. Calibration bars in (A) and (B), $500 \mu \mathrm{m}$. Calibration bars in (C-F), $150 \mu \mathrm{m}$.

means of a Hamilton syringe $(100 \mu \mathrm{M} ; 100 \mathrm{nl})$ and the effect was tested $15 \mathrm{~min}$. after application when the drug concentration was stabilized. Trains of electrical stimulus delivered in the PeFLH area $(50 \mathrm{~Hz} ; 50 \mu \mathrm{A} ; 500 \mathrm{~ms}$ of duration) increased the mean firing rate (calculated during $10 \mathrm{~s}$ before and $10 \mathrm{~s}$ after the stimulation train) of LC neurons from $2.8 \pm 0.8$ to $6.3 \pm 1.2$ spikes/s, $(n=12$; $p<0.001$; Figures 3A,C). The excitatory responses evoked by PeFLH stimulation train in LC neurons were blocked by the SB334867 (Figure 3B). Trains of electrical stimulus delivered in the PeFLH area did not increase the mean firing rate of LC neurons from $2.1 \pm 0.9$ to $2.8 \pm 0.6$ spikes $/ \mathrm{s}(n=12 ; p=0.12$; Figures 3B,C).

\section{PeF INHIBITION OF PnO ACTIVITY}

Most PnO neurons (15 out of 18 neurons; 83\%) decreased their spontaneous firing rate from $1.2 \pm 0.3 \mathrm{~Hz}$ in control conditions to $0.2 \pm 0.4 \mathrm{~Hz}(p<0.001) 10 \mathrm{~s}$ after application of a train of electrical stimuli delivered in the PeFLH area $(50 \mathrm{~Hz} ; 50 \mu \mathrm{A} ; 500 \mathrm{~ms}$ of duration; Figure 4, upper trace). To determine if the inhibitory response evoked by $\mathrm{PeF}$ stimulation was due to activation of GABAergic receptors, bicuculline (a $\mathrm{GABA}_{\mathrm{A}}$ receptor antagonist; $10 \mathrm{mM})$ was iontophoretically applied $(n=8)$. Bicuculline ejection increased the firing rate of $\mathrm{PnO}$ neurons to $4.9 \pm 0.9 \mathrm{~Hz}$. In
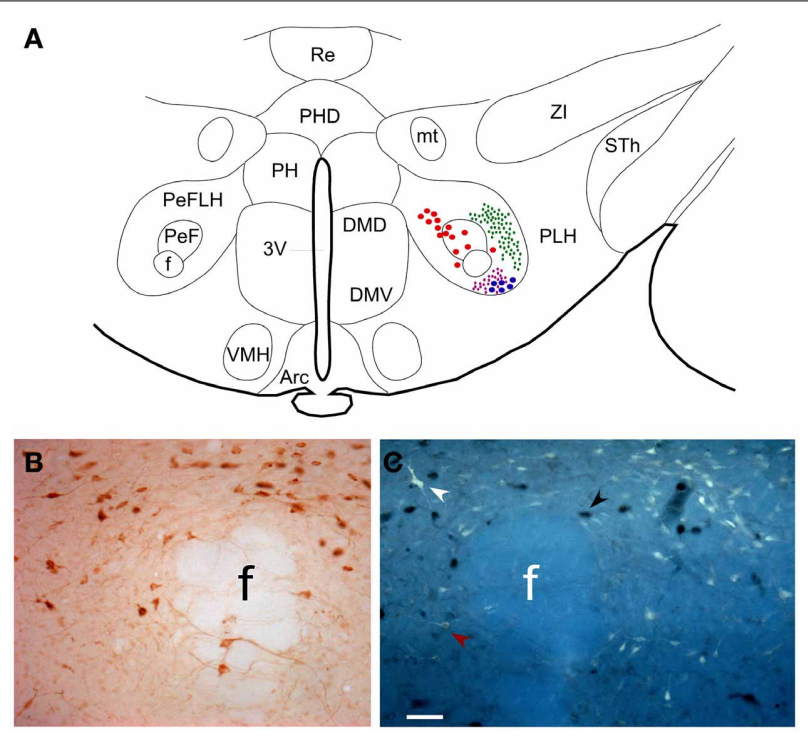

FIGURE 2 | (A) Schematic drawing of the hypothalamic area in a coronal section of rat brain at antero-posterior coordinates Bregma $-3.36 \mathrm{~mm}$. It is shown the distribution of neurons projecting to $\mathrm{PnO}$ (red dots) and LC (blue dots) and the distribution of fiber terminals arising $\mathrm{PnO}$ and $\mathrm{LC}$ are represented in green and purple small dots, respectively. (B) Microphotograph of PeF showing neurons immunocytochemically stained for anti-Orx. (C) Microphotograph showing adjacent section showed in (B) where Orx neurons are pointed by black arrowheads, FG neurons projecting to LC by white arrowheads and double labeled neurons by red arrowheads. Calibration bar: $50 \mu \mathrm{m}$. Abbreviations: 3V: 3rd ventricle; Arc: arcuate hypothalamic nucleus; DMD: dorsomedial hypothalamic nucleus, dorsal part; DMV: dorsomedial hypothalamic nucleus, ventral part; f: fornix; mt: mammillothalamic tract; PeF: perifornical nucleus; PeFLH: perifornical part of lateral hypothalamus area; $\mathrm{PH}$ : posterior hypothalamic nucleus; PHD: posterior hypothalamic area, dorsal part; PLH: peduncular part of lateral hypothalamus; Re: reuniens thalamic nucleus; Sth: subthalamic nucleus; VMH: ventromedial hypothalamic nucleus; ZI: zona incerta.

the presence of bicuculline, successive PeFLH stimulation trains did not change the firing rate of $\mathrm{PnO}$ neurons (Figure 4, lower trace), indicating that the inhibitory effect of PeF stimulation was due to activation of GABAergic receptors within the $\mathrm{PnO}$ nucleus, in agreement with previous reports (Nuñez et al., 2006a).

\section{PeF NEURONAL RESPONSES tO LC OR PnO STIMULATION}

Unit recordings were performed in the PeFLH area $(n=39)$. Neurons displayed a non-rhythmic discharge pattern with a mean spontaneous frequency of $1.3 \pm 0.3$ spikes/s. PeFLH neurons were identified by their stereotaxic coordinates after reconstruction of the electrode track.

The PeFLH area is implicated in the control of the sleepwakefulness cycle, facilitating wakefulness (see Introduction). We study the effect on PeFLH neuronal activity of electrical stimulation of brainstem areas implicated in the generation of wakefulness (LC nucleus) or REM sleep (PnO nucleus). Trains of electrical stimuli delivered in the LC nucleus $(50 \mathrm{~Hz} ; 50-100 \mu \mathrm{A}$; $500 \mathrm{~ms}$ of duration) induced a $1-10 \mathrm{~s}$ increase in firing rate, in most PeFLH neurons (21 out of 23 cells; 91\%; Figure 5A). The mean firing rate increased from $1.3 \pm 0.3$ spikes/s in spontaneous 


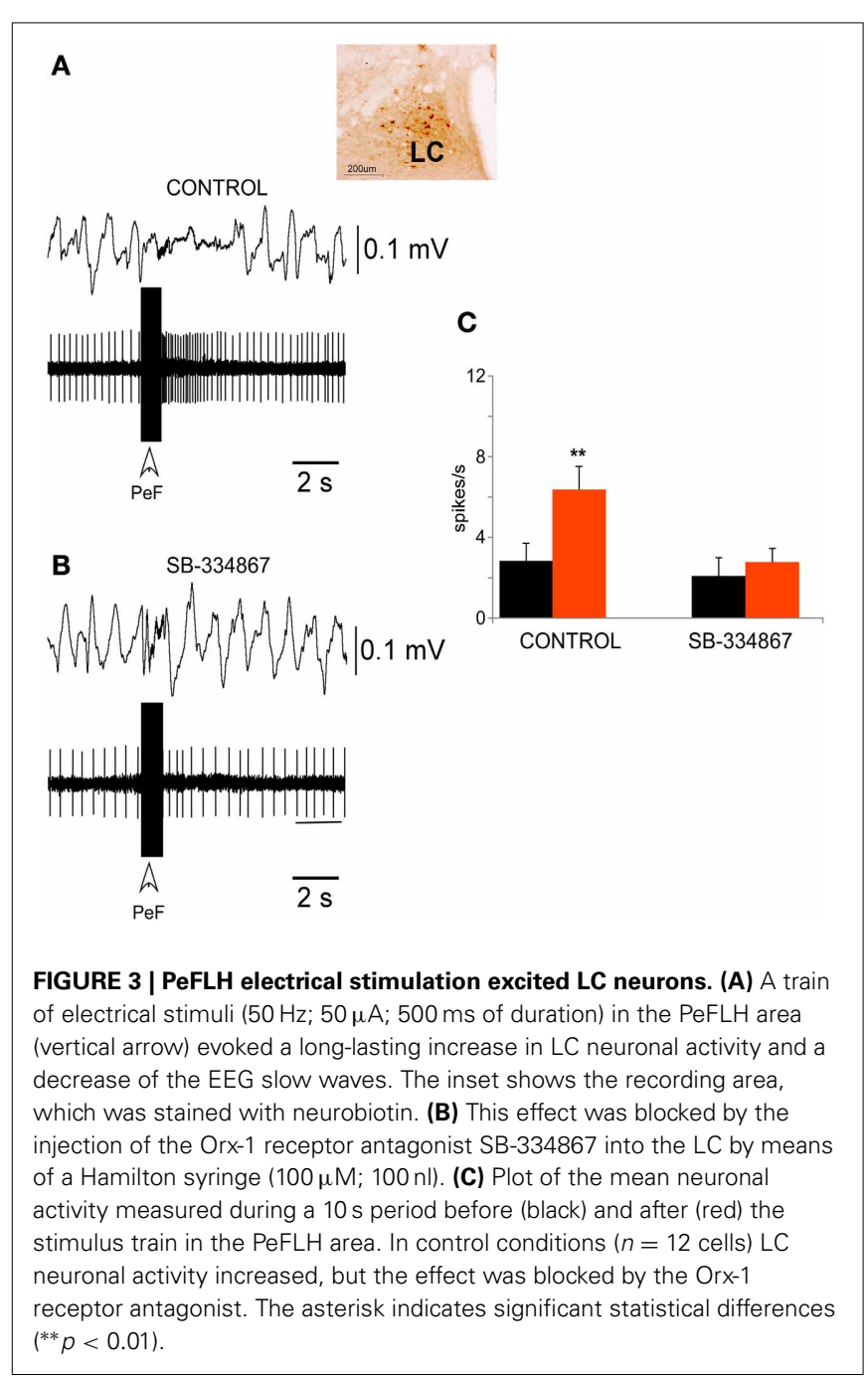

conditions to $8.6 \pm 1.4$ spikes/s $(n=21 ; p<0.001$; Figure 5C). The percentage of delta waves decreased during the same time period from $96.5 \pm 4.1$ to $79.8 \pm 2.9 \%(p<0.001)$.

The alkaloid reserpine which depletes catecholamines from nerve endings have been used. Reserpine administration ( $1 \mathrm{mg} / \mathrm{kg}$, once daily for three consecutive days) reduced the response of the PeFLH neurons to LC train stimulation. The LC-evoked rise in the firing rate was reduced in the presence of reserpine. Under reserpine activity rose from $1.3 \pm 0.5$ spikes/s before the stimulation train to $2.8 \pm 1.4$ spikes/s after the stimulation train; $n=8 ; p=0.015$; Figures $5 \mathrm{~B}, \mathrm{C}$, indicating that the LC-evoked excitation of PeF neurons was mediated by the activation of catecholaminergic fibers.

To determine if there is a reciprocal connection between the $\mathrm{PeFLH}$ area and $\mathrm{PnO}$ nucleus, electrical stimulation of the $\mathrm{PnO}$ nucleus $(0.5 \mathrm{~Hz} ; 50-100 \mu \mathrm{A} ; 0.1-0.3 \mathrm{~ms}$ of duration) was applied during unit recordings of PeFLH neurons. Trains of electrical stimulus delivered in the $\mathrm{PnO}$ nucleus $(50 \mathrm{~Hz} ; 50-100 \mu \mathrm{A} ; 500 \mathrm{~ms}$ of duration) induced a decrease of the firing rate in 14 out of 17 PeFLH neurons during 1-8 s (82\%; Figure 6A). The remaining neurons did not display significant changes in their firing

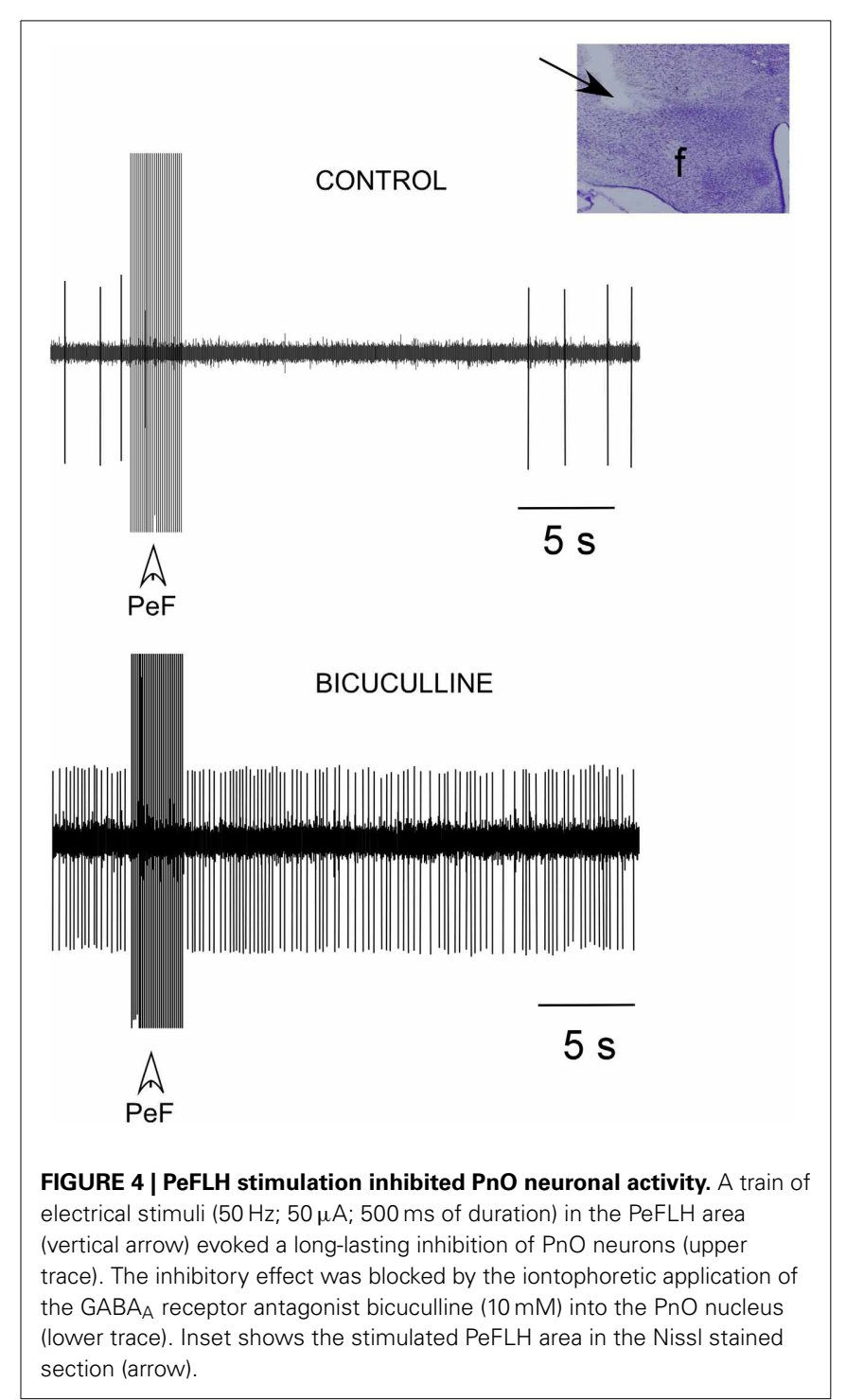

rate. The mean firing rate of these neurons affected by $\mathrm{PnO}$ train stimulation was $2.4 \pm 0.5 \mathrm{spikes} / \mathrm{s}$ in spontaneous conditions and this decreased to $1.4 \pm 0.6$ spikes/s during $2-5 \mathrm{~s}$ after the stimulation train $(n=14 ; p=0.009)$. PnO train stimulation induced a short-lasting decrease of slow waves, probably by activation of the basal forebrain through polysynaptic pathways (Camacho Evangelista and Reinoso Suarez, 1964; Nuñez et al., 2006b; Teruel-Marti et al., 2008).

The inhibition of PeFLH neuronal activity by PnO electrical stimulation was blocked by iontophoretic application of bicuculline ( $10 \mathrm{mM} ; n=8$; Figure $6 \mathrm{~B})$. Figure $5 \mathrm{C}$ shows the mean firing rate in control conditions $(n=14)$ and under bicuculline $(10 \mathrm{mM} ; n=8)$. The spontaneous firing rate of PeFLH neurons increased to $4.4 \pm 1.2 \mathrm{spikes} / \mathrm{s} 5 \mathrm{~min}$ after bicuculline application and, in these conditions, PnO stimulation did not alter the firing rate of the neurons $(5.0 \pm 0.9$ spikes/s), indicating that the $\mathrm{PnO}$-evoked inhibition of PeFLH neurons was dependent on the $\mathrm{GABA}_{\mathrm{A}}$ receptor activation. 


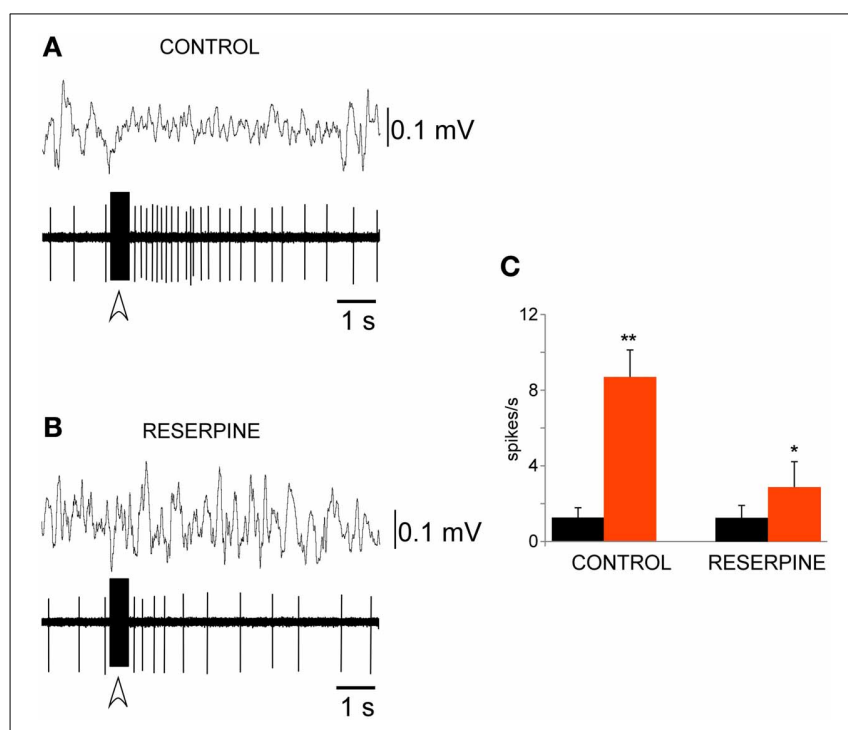

FIGURE 5 | LC stimulation evoked a long-lasting excitation of PeFLH neurons. (A) Train stimulation of the LC evoked an increase of PeF neuronal activity for $3 \mathrm{~s}$, with a simultaneous decrease in EEG slow waves. The stimulation train is indicated by the open arrow. (B) LC-evoked excitation was abolished in a reserpine-treated animal. (C) Plot of the mean firing rate calculated for the $10 \mathrm{~s}$ period before (black) and after (red) LC stimulation train in control animals ( $n=21$ cells) and in reserpine-treated animals ( $n=12$ cells). The LC-evoked excitation of PeFLH neurons was reduced after catecholaminergic depletion. The asterisk indicates significant statistical differences $\left(* p<0.05 ;{ }^{* *} p<0.01\right)$.

\section{DISCUSSION}

The present results demonstrate using anatomical and electrophysiological methods the existence of a neuronal network involving the PeFLH area, LC, and PnO nuclei that would control the sleep-wake cycle. The Orx PeF neurons favor EEG activation by excitatory projections to the LC nucleus and simultaneously block REM sleep generation by inhibition of $\mathrm{PnO}$ neurons through GABAergic receptors. This study also reveals that the LC and PnO nuclei exerted a feedback control on neuronal activity of PeFLH area in order to maintain a normal succession of stages during the sleep-wakefulness cycle. Top-down and bottom-up regulatory mechanisms are engaged to control the succession of sleep-wakefulness stages.

Both Orx-1 and Orx-2 receptors are expressed in the rodent brainstem (Greco and Shiromani, 2001; Marcus et al., 2001). Whereas the distribution of both receptors is quite similar in the PnO nucleus (Greco and Shiromani, 2001; Cluderay et al., 2002; Brischoux et al., 2008), LC nucleus shows a much more prominent expression for Orx-1 receptor mRNA and protein (Trivedi et al., 1998; Greco and Shiromani, 2001); Orx-2 receptors appear to be virtually absent in noradrenergic neurons of the LC nucleus (Brischoux et al., 2008). In agreement with these results, our data show that application of the Orx-1 receptor antagonist SB334867 into the LC nucleus prevents the excitatory effect evoked by PeFLH stimulation. The lesion of neurons expressing the Orx2 receptor in the lateral hypothalamus, by using the toxin Orx 2-saporin, have already revealed the implication of this receptor in different narcoleptic signs (Gerashchenko et al., 2001, 2003).

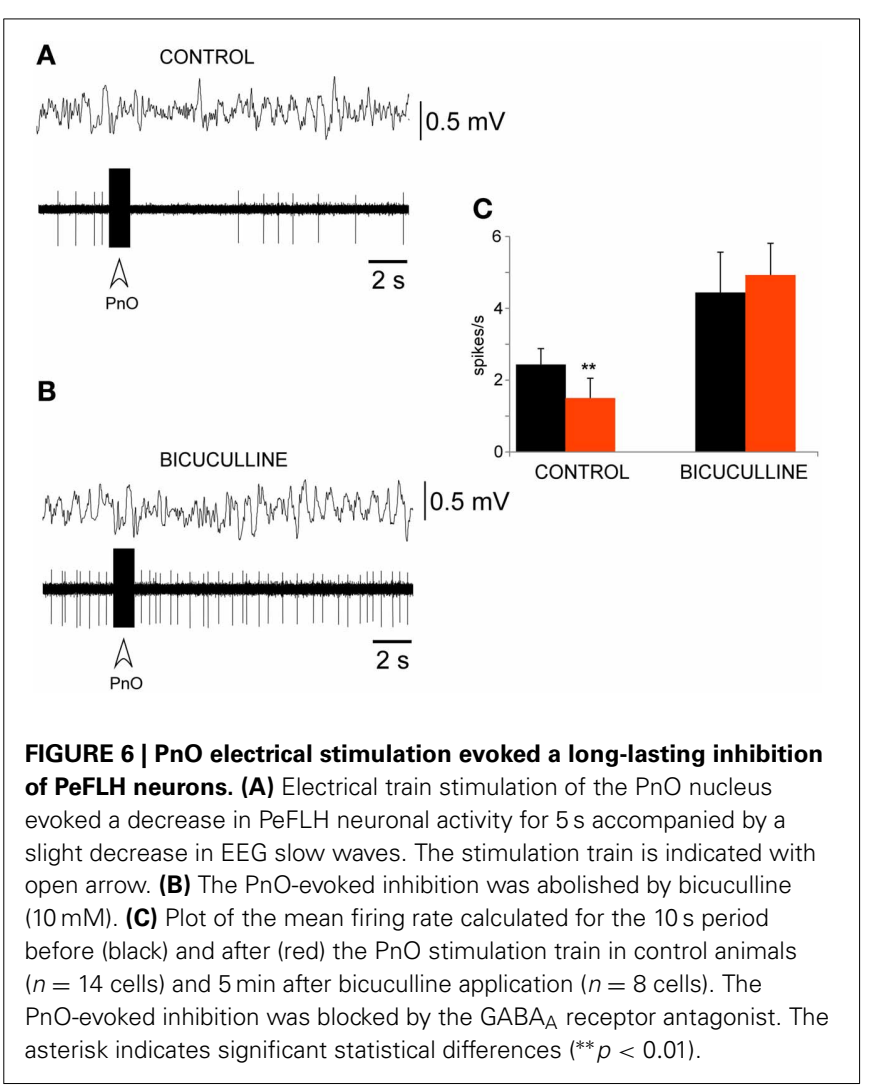

The additional utilization of selective Orx- 2 antagonists in the future could further help elucidate differential roles in regions expressing both receptors, such as the PnO.

The PeFLH area has been implicated in the regulation of behavioral arousal during wakefulness (Kilduff and Peyron, 2000; Siegel, 2004; Szymusiak and McGinty, 2008). This area contains Orx neurons mainly located in the PeF nucleus that are active during wakefulness and silent or with a low activity during nonREM and REM sleep (Alam et al., 2002; Koyama et al., 2003; Lee et al., 2005a,b; Suntsova et al., 2007). In a previous study we showed that Orx PeF neurons activate GABAergic receptors to inhibit PnO neurons, controlling the onset of REM sleep and thus, facilitating wakefulness (Nuñez et al., 2006a). In agreement with this observation, $\mathrm{Lu}$ and collaborators demonstrated that activation of PeF cells with bicuculline blocked the ability of pontine carbachol injections to elicit REM sleep (Lu et al., 2007). In the present study we show that there is a reciprocal connection between $\mathrm{PnO}$ and PeF nuclei. Both pathways have an inhibitory effect mediated by the activation of $\mathrm{GABA}_{\mathrm{A}}$ receptors because effects were blocked by local application of the $\mathrm{GABA}_{\mathrm{A}}$ receptor antagonist bicuculline. This experiment does not discard that other pathways could activated by PeFLH stimulation through other neurotransmitter actions. Consequently, when PeF neurons are active they block the possibility of REM sleep generation while $\mathrm{PnO}$ neurons activation during REM sleep inhibits PeF neurons and prevents wakefulness. Moreover, GABAergic sleepactive anterior hypothalamic neurons project to the PeF nucleus and GABA release is increased in this region during slow wave sleep (Nitz and Siegel, 1996; Saper et al., 2001, 2005; Uschakov 
et al., 2006). Thus, during slow wave and REM sleep PeF Orx neurons are inhibited. The absence of Orx is associated with narcolepsy, a disorder manifested by an uncontrollable occurrence of REM sleep (Chemelli et al., 1999; Lin et al., 1999; Thannickal et al., 2000). In agreement with this, Orx knock-out mice show an increase of slow wave and REM sleep during the darkness period, whereas wakefulness is decreased (Chemelli et al., 1999).

In this study we further demonstrated in vivo that PeF neurons facilitate wakefulness by direct excitation of LC neurons, which contribute to arousal by excitation of thalamic and cortical neurons (McCormick and Prince, 1988; McCormick, 1989; AstonJones, 2005). Previous studies in brain slices or neuronal cultures have demonstrated that Orx depolarizes LC neurons, increasing their firing rate (Soffin et al., 2002; Murai and Akaike, 2005). Also, the firing rates of LC neurons increased after microiontophoretic injection of Orx (Bourgin et al., 2000). LC neurons recorded in the present study showed similar spontaneous firing rate in control conditions from anesthetized rats that previous studies (Aston-Jones and Bloom, 1981; Bourgin et al., 2000) and also are consistent with these previous studies in demonstrating that Orx increases neuronal excitability in the LC nucleus through the activation of the Orx-1 receptor, since excitability is diminished by the Orx-1 receptor antagonist SB-334867 (Gompf and Aston-Jones, 2008). Orx innervation of LC neurons projecting to the cortex has been reported recently (Cid-Pellitero and Garzon, 2011). This Orx innervation probably supplies excitatory inputs to LC nucleus that are critical for cortical activation in transitions from sleep to wakefulness and during EEG activation.

The activity of LC neurons is involved in maintenance of wakefulness and EEG activation. These neurons are active during wakefulness, decrease their firing rate during slow wave sleep and are silent during REM sleep (Hobson and McCarley, 1975; AstonJones and Bloom, 1981). Unilateral lesions of the LC nucleus in cats enhance REM sleep (Caballero and De Andres, 1986). Carter and collaborators, using an optogenetic approach to stimulate or inhibit LC neurons found that silencing LC neurons blocked Orx-mediated sleep-to-wakefulness transitions while increasing the excitability of LC neurons enhanced these transitions (Carter et al., 2012, 2013).

Consequently with the above results, the LC nucleus plays a key role in regulating the sleep-wakefulness cycle. To favor the wakefulness stage, LC neurons activate PeF neurons by a direct pathway from LC nucleus to PeFLH area, as shown here. Moreover, electrical stimulation of LC nucleus induced an increase in the neuronal firing rate of $\mathrm{PeF}$ neurons by activation of catecholaminergic receptors. The lateral hypothalamus receives a moderately dense noradrenergic innervation (Baldo et al., 2003), most of which arises from outside the LC nucleus (Yoshida et al., 2006). Our study shows that neurons labeled after retrograde tracer injections in LC nucleus were located in the ventral sector of PeFLH area. Previous studies have described dense projections from PeFLH to the LC in the rat (Luppi et al., 1995; España et al., 2005; Lee et al., 2005b) and in the cat (Torterolo et al., 2013). The PeFLH neurons projecting to the LC distribute within the hypothalamic region containing the Orx cell group without any observed rostrocaudal or mediolateral topography, as occur in our experiments. However, retrogradely-labeled lateral hypothalamic neurons after
LC nucleus tracer injections have been reported to locate also in the dorsal half of the Orx-containing cell group (España et al., 2005). This difference may be due to the tracer infusion volume or the tracer uptake.

It is reasonable to believe that both effects, inhibition of REM sleep generation and facilitation of arousal, could be performed by the same PeF neuronal population. However, our anatomical results indicate there are two different neuronal populations sending separate projections to $\mathrm{PnO}$ and LC nuclei. In fact, injections of retrograde tracers in $\mathrm{PnO}$ nucleus resulted in labeled neurons in the PeF nucleus and in the medial sector of the PeFLH area, while neurons labeled after retrograde tracer injections in LC nucleus were located in the ventral sector of PeFLH area. Taken together, these results suggest the existence of a neuronal network between the lateral hypothalamus and brainstem structures that may control the appropriate succession of the stages during sleepwakefulness cycle. Moreover, Orx neurons of the PeFLH area seem to be an important organizer of the wakefulness and sleep stages based on their anatomical projections and synaptic interactions with different brainstem "sleep generators." Thus, some sleep disorders such as narcolepsy or insomnia may be due to alterations of the Orx system.

\section{AUTHOR CONTRIBUTIONS}

Conceived and designed the experiments: Angel Núñez, Miguel Garzón, and Margarita L. Rodrigo-Angulo. Performed and analyzed electrophysiological experiments: Angel Núñez and Silvia Tortorella. Performed and analyzed anatomical experiments: Miguel Garzón and Margarita L. Rodrigo-Angulo. Wrote the paper: Angel Núñez, Miguel Garzón, and Margarita L. RodrigoAngulo.

\section{ACKNOWLEDGMENTS}

This work was supported by grant from Ministerio de Economia y Competitividad (BFU2009-06991). We thank G. de la Fuente and M. Callejo for technical assistance and C. F. Warren for revision of English language usage.

\section{REFERENCES}

Abrahamson, E. E., and Moore, R. Y. (2001). The posterior hypothalamic area: chemoarchitecture and afferent connections. Brain Res. 889, 1-22. doi: 10.1016/S0006-8993(00)03015-8

Alam, M. N., Gong, H., Alam, T., Jaganath, R., McGinty, D., and Szymusiak, R. (2002). Sleep-waking discharge patterns of neurons recorded in the rat perifornical lateral hypothalamic area. J. Physiol. (Lond.) 538, 619-631. doi: 10.1113/jphysiol.2001.012888

Aston-Jones, G. (2005). Brain structures and receptors involved in alertness. Sleep Med. 6(Suppl. 1), S3-S7. doi: 10.1016/S1389-9457(05)80002-4

Aston-Jones, G., and Bloom, F. E. (1981). Activity of norepinephrine-containing locus coeruleus neurons in behaving rats anticipates fluctuations in the sleepwaking cycle. J. Neurosci. 1, 876-886.

Baldo, B. A., Daniel, R. A., Berridge, C. W., and Kelley, A. E. (2003). Overlapping distributions of orexin/hypocretin- and dopamine-beta-hydroxylase immunoreactive fibers in rat brain regions mediating arousal, motivation, and stress. J. Comp. Neurol. 464, 220-237. doi: 10.1002/cne.10783

Bernard, R., Lydic, R., and Baghdoyan, H. A. (2003). Hypocretin-1 causes G protein activation and increases ACh release in rat pons. Eur. J. Neurosci. 18, 1775-1785. doi: 10.1046/j.1460-9568.2003.02905.x

Bernard, R., Lydic, R., and Baghdoyan, H. A. (2006). Hypocretin (orexin) receptor subtypes differentially enhance acetylcholine release and activate g protein 
subtypes in rat pontine reticular formation. J. Pharmacol. Exp. Ther. 317, 163-171. doi: 10.1124/jpet.105.097071

Beuckmann, C. T., Sinton, C. M., Williams, S. C., Richardson, J. A., Hammer, R. E., Sakurai, T., et al. (2004). Expression of a poly-glutamine-ataxin-3 transgene in orexin neurons induces narcolepsy-cataplexy in the rat. J. Neurosci. 24, 4469-4477. doi: 10.1523/JNEUROSCI.5560-03.2004

Bittencourt, J. C., Presse, F., Arias, C., Peto, C., Vaughan, J., Nahon, J. L., et al. (1992). The melanin-concentrating hormone system of the rat brain: an immuno- and hybridization histochemical characterization. J. Comp. Neurol. 319, 218-245. doi: 10.1002/cne.903190204

Bourgin, P., Huitron-Resendiz, S., Spier, A. D., Fabre, V., Morte, B., Criado, J. R., et al. (2000). Hypocretin-1 modulates rapid eye movement sleep through activation of locus coeruleus neurons. J. Neurosci. 20, 7760-7765.

Brischoux, F., Mainville, L., and Jones, B. E. (2008). Muscarinic-2 and orexin-2 receptors on GABAergic and other neurons in the rat mesopontine tegmentum and their potential role in sleep-wake state control. J. Comp. Neurol. 510, 607-630. doi: 10.1002/cne.21803

Burlet, S., Tyler, C. J., and Leonard, C. S. (2002). Direct and indirect excitation of laterodorsal tegmental neurons by hypocretin/orexin peptides: implications for wakefulness and narcolepsy. J. Neurosci. 22, 2862-2872.

Caballero, A., and De Andres, I. (1986). Unilateral lesions in locus coeruleus area enhance paradoxical sleep. Electroencephalogr. Clin. Neurophysiol. 64, 339-346. doi: 10.1016/0013-4694(86)90158-6

Camacho Evangelista, A., and Reinoso Suarez, F. (1964). Activating and synchronizing centers in cat brain: electroencephalograms after lesions. Science 146, 268-270. doi: 10.1126/science.146.3641.268

Carter, M. E., Brill, J., Bonnavion, P., Huguenard, J. R., Huerta, R., and de Lecea, L. (2012). Mechanism for hypocretin-mediated sleep-to-wake transitions. Proc. Natl. Acad. Sci. U.S.A. 109, E2635-E2644. doi: 10.1073/pnas.1202526109

Carter, M. E., de Lecea, L., and Adamantidis, A. (2013). Functional wiring of hypocretin and LC-NE neurons: implications for arousal. Front. Behav. Neurosci. 7:43. doi: 10.3389/fnbeh.2013.00043

Chemelli, R. M., Willie, J. T., Sinton, C. M., Elmquist, J. K., Scammell, T., Lee, C., et al. (1999). Narcolepsy in orexin knockout mice: molecular genetics of sleep regulation. Cell 98, 437-451. doi: 10.1016/S0092-8674(00)81973-X

Cid-Pellitero, E. D., and Garzon, M. (2011). Hypocretin1/OrexinA-containing axons innervate locus coeruleus neurons that project to the rat medial prefrontal cortex. Implication in the sleep-wakefulness cycle and cortical activation. Synapse 65, 843-857. doi: 10.1002/syn.20912

Cluderay, J. E., Harrison, D. C., and Hervieu, G. J. (2002). Protein distribution of the orexin-2 receptor in the rat central nervous system. Regul. Pept. 104, 131-144. doi: 10.1016/S0167-0115(01)00357-3

de Lecea, L., Kilduff, T. S., Peyron, C., Gao, X., Foye, P. E., Danielson, P. E., et al. (1998). The hypocretins: hypothalamus-specific peptides with neuroexcitatory activity. Proc. Natl. Acad. Sci. U.S.A. 95, 322-327. doi: 10.1073/pnas.95.1.322

Eggermann, E., Serafin, M., Bayer, L., Machard, D., Saint-Mleux, B., Jones, B. E., et al. (2001). Orexins/hypocretins excite basal forebrain cholinergic neurones. Neuroscience 108, 177-181. doi: 10.1016/S0306-4522(01)00512-7

Erami, E., Azhdari-Zarmehri, H., Ghasemi-Dashkhasan, E., Esmaeili, M. H., and Semnanian, S. (2012). Intra-paragigantocellularis lateralis injection of orexin-A has an antinociceptive effect on hot plate and formalin tests in rat. Brain Res. 1478, 16-23. doi: 10.1016/j.brainres.2012.08.013

España, R. A., Baldo, B. A., Kelley, A. E., and Berridge, C. W. (2001). Wakepromoting and sleep-suppressing actions of hypocretin (orexin): basal forebrain sites of action. Neuroscience 106, 699-715. doi: 10.1016/S0306-4522(01)00319-0

España, R. A., Reis, K. M., Valentino, R. J., and Berridge, C. W. (2005). Organization of hypocretin/orexin efferents to locus coeruleus and basal forebrain arousalrelated structures. J. Comp. Neurol. 481, 160-178. doi: 10.1002/cne.20369

Garzón, M., De Andrés, I., and Reinoso-Suárez, F. (1998). Sleep patterns after carbachol delivery in the ventral oral pontine tegmentum of the cat. Neuroscience 83, 1137-1144. doi: 10.1016/S0306-4522(97)00494-6

Gerashchenko, D., Blanco-Centurion, C., Greco, M. A., and Shiromani, P. J. (2003). Effects of lateral hypothalamic lesion with the neurotoxin hypocretin-2-saporin on sleep in Long-Evans rats. Neuroscience 116, 223-235. doi: 10.1016/S03064522(02)00575-4

Gerashchenko, D., Kohls, M. D., Greco, M., Waleh, N. S., Salin-Pascual, R., Kilduff, T. S., et al. (2001). Hypocretin-2-saporin lesions of the lateral hypothalamus produce narcoleptic-like sleep behavior in the rat. J. Neurosci. 21, 7273-7283.
Gompf, H. S., and Aston-Jones, G. (2008). Role of orexin input in the diurnal rhythm of locus coeruleus impulse activity. Brain Res. 1224, 43-52. doi: 10.1016/j.brainres.2008.05.060

Greco, M. A., and Shiromani, P. J. (2001). Hypocretin receptor protein and mRNA expression in the dorsolateral pons of rats. Mol. Brain Res. 88, 176-182. doi: 10.1016/S0169-328X(01)00039-0

Guilleminault, C., and Fromherz, S. (2005). "Narcolepsy: diagnosis and management," in Principles and Practice of Sleep Medicine, eds M. H. Kryger, T. I. Roth, and W. C. Dement (Philadelphia, PA: Elsevier Saunders), 780-790. doi: 10.1016/B0-72-160797-7/50072-0

Hagan, J. J., Leslie, R. A., Patel, S., Evans, M. L., Wattam, T. A., Holmes, S., et al. (1999). Orexin A activates locus coeruleus cell firing and increases arousal in the rat. Proc. Natl. Acad. Sci. U.S.A. 96, 10911-10916. doi: 10.1073/pnas.96.19.10911

Hara, J., Beuckmann, C. T., Nambu, T., Willie, J. T., Chemelli, R. M., Sinton, C. M., et al. (2001). Genetic ablation of orexin neurons in mice results in narcolepsy, hypophagia, and obesity. Neuron 30, 345-354. doi: 10.1016/S08966273(01)00293-8

Hobson, J. A., and McCarley, R. W. (1975). Sleep cycle oscillation: reciprocal discharge by two brainstem neuronal groups. Science 189, 55-58. doi: 10.1126/science. 1094539

Horner, R. L., and Kubin, L. (1999). Pontine carbachol elicits multiple rapid eye movement sleep-like neural events in urethane-anaesthetized rats. Neuroscience 93, 215-226. doi: 10.1016/S0306-4522(99)00126-8

Horvath, T. L., Peyron, C., Diano, S., Ivanov, A., Aston-Jones, G., Kilduff, T. S., et al. (1999). Hypocretin (orexin) activation and synaptic innervation of the locus coeruleus noradrenergic system. J. Comp. Neurol. 415, 145-159. doi: 10.1002/(SICI)1096-9861(19991213)415:2<145::AID-CNE1>3.0.CO;2-2

Ivanov, A., and Aston-Jones, G. (2000). Hypocretin/orexin depolarizes and decreases potassium conductance in locus coeruleus neurons. Neuroreport 11, 1755-1758. doi: 10.1097/00001756-200006050-00031

Jones, B. E. (2008). Modulation of cortical activation and behavioral arousal by cholinergic and orexinergic systems. Ann. N.Y. Acad. Sci. 1129, 26-34. doi: 10.1196/annals.1417.026

Kilduff, T. S., and Peyron, C. (2000). The hypocretin/orexin ligand-receptor system: implications for sleep and sleep disorders. Trends Neurosci. 23, 359-365. doi: 10.1016/S0166-2236(00)01594-0

Kohlmeier, K. A., Burns, J., Reiner, P. B., and Semba, K. (2002). Substance P in the descending cholinergic projection to REM sleep-induction regions of the rat pontine reticular formation: anatomical and electrophysiological analyses. Eur. J. Neurosci. 15, 176-196. doi: 10.1046/j.0953-816x.2001.01829.x

Koyama, Y., Takahashi, K., Kodama, T., and Kayama, Y. (2003). State-dependent activity of neurons in the perifornical hypothalamic area during sleep and waking. Neuroscience 119, 1209-1219. doi: 10.1016/S0306-4522(03)00173-8

Lee, M. G., Hassani, O. K., and Jones, B. E. (2005a). Discharge of identified orexin/hypocretin neurons across the sleep-waking cycle. J. Neurosci. 25, 6716-6720. doi: 10.1523/JNEUROSCI.1887-05.2005

Lee, H. S., Lee, B. Y., and Waterhouse, B. D. (2005b). Retrograde study of projections from the tuberomammillary nucleus to the dorsal raphe and the locus coeruleus in the rat. Brain Res. 1043, 65-75. doi: 10.1016/j.brainres.2005.02.050

Lin, L., Faraco, J., Li, R., Kadotani, H., Rogers, W., Lin, X., et al. (1999). The sleep disorder canine narcolepsy is caused by a mutation in the hypocretin (orexin) receptor 2 gene. Cell 98, 365-376. doi: 10.1016/S0092-8674(00)81965-0

Lu, J. W., Fenik, V. B., Branconi, J. L., Mann, G. L., Rukhadze, I., and Kubin, L. (2007). Disinhibition of perifornical hypothalamic neurones activates noradrenergic neurones and blocks pontine carbachol-induced REM sleep-like episodes in rats. J. Physiol. 582, 553-567. doi: 10.1113/jphysiol.2007.127613

Luppi, P. H., Aston-Jones, G., Akaoka, H., Chouvet, G., and Jouvet, M. (1995). Afferent projections to the rat locus coeruleus demonstrated by retrograde and anterograde tracing with cholera-toxin B subunit and Phaseolus vulgaris leucoagglutinin. Neuroscience 65, 119-160. doi: 10.1016/0306-4522(94)00481-J

Marcus, J. N., Aschkenasi, C. J., Lee, C. E., Chemelli, R. M., Saper, C. B., Yanagisawa, M., et al. (2001). Differential expression of orexin receptors 1 and 2 in the rat brain. J. Comp. Neurol. 435, 6-25. doi: 10.1002/cne.1190

McCormick, D. A. (1989). Cholinergic and noradrenergic modulation of thalamocortical processing. Trends Neurosci. 12, 215-221. doi: 10.1016/01662236(89)90125-2

McCormick, D. A., and Prince, D. A. (1988). Noradrenergic modulation of firing pattern in guinea pig and cat thalamic neurons, in vitro. J. Neurophysiol. 59, 978-996. 
McGinty, D., and Szymusiak, R. (2003). Hypothalamic regulation of sleep and arousal. Front. Biosci. 8, s1074-s1083. doi: 10.2741/1159

Mileykovskiy, B. Y., Kiyashchenko, L. I., and Siegel, J. M. (2005). Behavioral correlates of activity in identified hypocretin/orexin neurons. Neuron $46,787-798$. doi: 10.1016/j.neuron.2005.04.035

Murai, Y., and Akaike, T. (2005). Orexins cause depolarization via nonselective cationic and $\mathrm{K}+$ channels in isolated locus coeruleus neurons. Neurosci. Res. 51, 55-65. doi: 10.1016/j.neures.2004.09.005

Nishino, S., Ripley, B., Overeem, S., Lammers, G. J., and Mignot, E. (2000). Hypocretin (orexin) deficiency in human narcolepsy. Lancet 355, 39-40. doi: 10.1016/S0140-6736(99)05582-8

Nitz, D., and Siegel, J. M. (1996). GABA release in posterior hypothalamus across sleep-wake cycle. Am. J. Physiol. 271, R1707-R1712.

Nuñez, A., Moreno-Balandran, M. E., Rodrigo-Angulo, M. L., Garzon, M., and De Andres, I. (2006a). Relationship between the perifornical hypothalamic area and oral pontine reticular nucleus in the rat. Possible implication of the hypocretinergic projection in the control of rapid eye movement sleep. Eur. J. Neurosci. 24, 2834-2842. doi: 10.1111/j.1460-9568.2006.05159.x

Nuñez, A., Cervera-Ferri, A., Olucha-Bordonau, F., Ruiz-Torner, A., and Teruel, V. (2006b). Nucleus incertus contribution to hippocampal theta rhythm generation. Eur. J. Neurosci. 23, 2731-2738. doi: 10.1111/j.1460-9568.2006. 04797.x

Nuñez, A., Rodrigo-Angulo, M. L., De Andres, I., and Reinoso-Suarez, F. (2002). Firing activity and postsynaptic properties of morphologically identified neurons of ventral oral pontine reticular nucleus. Neuroscience 115, 1165-1175. doi: 10.1016/S0306-4522(02)00478-5

Paxinos, G., and Watson, C. (2007). The Rat Brain in Stereotaxic Coordinates. San Diego, CA: Academic Press.

Peyron, C., Faraco, J., Rogers, W., Ripley, B., Overeem, S., Charnay, Y., et al. (2000). A mutation in a case of early onset narcolepsy and a generalized absence of hypocretin peptides in human narcoleptic brains. Nat. Med. 6, 991-997. doi: $10.1038 / 79690$

Peyron, C., Tighe, D. K., van den Pol, A. N., de Lecea, L., Heller, H. C., Sutcliffe, J. G., et al. (1998). Neurons containing hypocretin (orexin) project to multiple neuronal systems. J. Neurosci. 18, 9996-10015.

Reinoso-Suárez, F., De Andrés, I., Rodrigo-Angulo, M. L., de la Roza, C., Nuñez, A., and Garzón, M. (1999). The anatomy of dreaming, and REM sleep. Eur. J. Anat. 3, 163-175.

Reinoso-Suarez, F., de Andres, I., Rodrigo-Angulo, M. L., and Garzon, M. (2001). Brain structures and mechanisms involved in the generation of REM sleep. Sleep Med. Rev. 5, 63-77. doi: 10.1053/smrv.2000.0136

Reinoso-Suárez, F., de Andrés, I., Rodrigo-Angulo, M. L., and Rodriguez-Veiga, E. (1994). Location and anatomical connections of a paradoxical sleep induction site in the brainstem of the cat. Eur. J. Neurosci. 6, 1829-1836. doi: 10.1111/j.1460-9568.1994.tb00575.x

Rodrigo-Angulo, M. L., Heredero, S., Rodriguez-Veiga, E., and Reinoso-Suarez, F. (2008). GABAergic and non-GABAergic thalamic, hypothalamic and basal forebrain projections to the ventral oral pontine reticular nucleus: their implication in REM sleep modulation. Brain Res. 1210, 116-125. doi: 10.1016/j.brainres.2008.02.095

Sakurai, T. (2005). Roles of orexin/hypocretin in regulation of sleep/wakefulness and energy homeostasis. Sleep Med. Rev. 9, 231-241. doi: 10.1016/j.smrv.2004.07.007

Sakurai, T., Amemiya, A., Ishii, M., Matsuzaki, I., Chemelli, R. M., Tanaka, H., et al. (1998). Orexins and orexins receptors: a family of hypothalamic neuropeptides and $G$ protein-coupled receptors that regulate feeding behavior. Cell 92, 573-585. doi: 10.1016/S0092-8674(00) 80949-6

Saper, C. B., Chou, T. C., and Scammell, T. E. (2001). The sleep switch: hypothalamic control of sleep and wakefulness. Trends Neurosci. 24, 726-731. doi: 10.1016/S0166-2236(00)02002-6

Saper, C. B., Lu, J., Chou, T. C., and Gooley, J. (2005). The hypothalamic integrator for circadian rhythms. Trends Neurosci. 28, 152-157. doi: 10.1016/j.tins.2004.12.009

Sasaki, K., Suzuki, M., Mieda, M., Tsujino, N., Roth, B., and Sakurai, T. (2011). Pharmacogenetic modulation of orexin neurons alters sleep/wakefulness states in mice. PLOS ONE 6:e20360. doi: 10.1371/journal.pone.0020360

Siegel, J. M. (2004). Hypocretin (orexin): role in normal behavior and neuropathology. Annu. Rev. Psychol. 55, 125-148. doi: 10.1146/annurev.psych.55.090902.141545
Soffin, E. M., Evans, M. L., Gill, C. H., Harries, M. H., Benham, C. D., and Davies, C. H. (2002). SB-334867-A antagonises orexin mediated excitation in the locus coeruleus. Neuropharmacology 42, 127-133. doi: 10.1016/S00283908(01)00156-3

Suntsova, N., Guzman-Marin, R., Kumar, S., Alam, M. N., Szymusiak, R., and McGinty, D. (2007). The median preoptic nucleus reciprocally modulates activity of arousal-related and sleep-related neurons in the perifornical lateral hypothalamus. J. Neurosci. 27, 1616-1630. doi: 10.1523/JNEUROSCI.349806.2007

Szymusiak, R., and McGinty, D. (2008). Hypothalamic regulation of sleep and arousal. Ann. N.Y. Acad. Sci. 1129, 275-286. doi: 10.1196/annals.1417.027

Takahashi, K., Wang, Q. P., Guan, J. L., Kayama, Y., Shioda, S., and Koyama, Y. (2005). State-dependent effects of orexins on the serotonergic dorsal raphe neurons in the rat. Regul. Pept. 126, 43-47. doi: 10.1016/j.regpep.2004.08.009

Teruel-Marti, V., Cervera-Ferri, A., Nuñez, A., Valverde-Navarro, A. A., OluchaBordonau, F. E., and Ruiz-Torner, A. (2008). Anatomical evidence for a pontoseptal pathway via the nucleus incertus in the rat. Brain Res. 1218, 87-96. doi: 10.1016/j.brainres.2008.04.022

Thakkar, M. M., Ramesh, V., Strecker, R. E., and McCarley, R. W. (2001). Microdialysis perfusion of orexin-A in the basal forebrain increases wakefulness in freely behaving rats. Arch. Ital. Biol. 139, 313-328.

Thannickal, T. C., Moore, R. Y., Nienhuis, R., Ramanathan, L., Gulyani, S., Aldrich, M., et al. (2000). Reduced number of hypocretin neurons in human narcolepsy. Neuron 27, 469-474. doi: 10.1016/S0896-6273(00)00058-1

Torterolo, P., Sampogna, S., and Chase, M. H. (2013). Hypocretinergic and nonhypocretinergic projections from the hypothalamus to the REM sleep executive area of the pons. Brain Res. 1491, 68-77. doi: 10.1016/j.brainres.2012.10.050

Trivedi, P., Yu, H., MacNeil, D. J., Van der Ploeg, L. H., and Guan, X. M. (1998). Distribution of orexin receptor mRNA in the rat brain. FEBS Lett. 438, 71-75. doi: 10.1016/S0014-5793(98)01266-6

Uschakov, A., Gong, H., McGinty, D., and Szymusiak, R. (2006). Sleep active neurons in the preoptic area project to hypothalamic paraventricular nucleus and perifornical lateral hypothalamus. Eur. J. Neurosci. 23, 3284-3296. doi: 10.1111/j.1460-9568.2006.04860.x

Vaughan, J. M., Fischer, W. H., Hoeger, C., Rivier, J., and Vale, W. (1989). Characterization of melanin-concentrating hormone from rat hypothalamus. Endocrinology 125, 1660-1665. doi: 10.1210/endo-125-3-1660

Willie, J. T., Chemelli, R. M., Sinton, C. M., Tokita, S., Williams, S. C., Kisanuki, Y. Y., et al. (2003). Distinct narcolepsy syndromes in orexin receptor-2 and orexin null mice: molecular genetic dissection of non-REM and REM sleep regulatory processes. Neuron 38, 715-730. doi: 10.1016/S0896-6273(03)00330-1

Xi, M. C., Morales, F. R., and Chase, M. H. (2001). Effects on sleep and wakefulness of the injection of hypocretin-1 (orexin-A) into the laterodorsal tegmental nucleus of the cat. Brain Res. 901, 259-264. doi: 10.1016/S0006-8993(01) 02317-4

Yamanaka, A., Tsujino, N., Funahashi, H., Honda, K., Guan, J. L., Wang, Q. P., et al. (2002). Orexins activate histaminergic neurons via the orexin 2 receptor. Biochem. Biophys. Res. Commun. 290, 1237-1245. doi: 10.1006/bbrc.2001.6318

Yoshida, K., McCormack, S., Espana, R. A., Crocker, A., and Scammell, T. E. (2006). Afferents to the orexin neurons of the rat brain. J. Comp. Neurol. 494, 845-861. doi: 10.1002/cne.20859

Conflict of Interest Statement: The authors declare that the research was conducted in the absence of any commercial or financial relationships that could be construed as a potential conflict of interest.

Received: 30 August 2013; accepted: 30 October 2013; published online: 19 November 2013.

Citation: Tortorella S, Rodrigo-Angulo ML, Núñez A and Garzón M (2013) Synaptic interactions between perifornical lateral hypothalamic area, locus coeruleus nucleus and the oral pontine reticular nucleus are implicated in the stage succession during sleep-wakefulness cycle. Front. Neurosci. 7:216. doi: 10.3389/fnins.2013.00216

This article was submitted to Neuropharmacology, a section of the journal Frontiers in Neuroscience.

Copyright () 2013 Tortorella, Rodrigo-Angulo, Núñez and Garzón. This is an openaccess article distributed under the terms of the Creative Commons Attribution License (CC BY). The use, distribution or reproduction in other forums is permitted, provided the original author(s) or licensor are credited and that the original publication in this journal is cited, in accordance with accepted academic practice. No use, distribution or reproduction is permitted which does not comply with these terms. 